\title{
Entremeios etários: Os “novos” sujeitos da Educação de Jovens e Adultos
}

\author{
João Luiz Simplício Porto ${ }^{1}$ \\ Hiran Pinel ${ }^{2}$ \\ Adriana Rosely Magro ${ }^{3}$
}

\section{Resumo}

O objetivo desse artigo é do de produzir algumas tensões, inquietações e resistências possíveis que contribuam com a leitura do mundo da Educação de Jovens e Adultos, como objetivo. Idas e vindas ao "porão", circulação pelos "cômodos" e potencialização das ideias num "sótão" que, certamente, carece urgentemente das mesmas. Para alcançar essa proposta, os autores ensaiam trilhar caminhos inspirados na fenomenologia descritiva, imbricada com a educação. Politicamente no Brasil, como nação, não foram garantidos, a contento, o direito e o acesso à Educação, como previsto no Estatuto da Criança e do Adolescente - ECA (1990), e a Educação de Jovens e Adultos tem sido o destino de crianças, adolescentes e jovens como forma precária de dar respostas a essas ausências.

Palavras-chave: Educação de Jovens e Adultos; Juventude; Exclusão.

\section{Age interrelations: The "new" subjects in youth and adult education}

\section{Abstract}

The objective of this article is to produce some tensions, restlessness and resistances possible that contribute to the reading of the world of Youth and Adult Education, as an objective. Movement to the "basement", circulation through the "rooms" and potentialization of ideas in an "attic", which, of course, urgently needs them. To reach this proposal, the authors try to trace paths inspired by descriptive phenomenology, imbricated with education. Politically in Brazil, as a nation, the right and access to Education, as provided for in the Statute of the Child and the Adolescent - ECA (1990), were not guaranteed, and the education of young people and adults has been the fate of children adolescents and young people as a precarious way of responding to these.

Keywords: Youth and Adult Education; Youth; Exclusion.

\section{Introdução}

Quando Veiga-Neto (2012) traz à luz a parábola da casa, de Bachelard (2003), nos informa da necessidade de entendermos nosso "porão" como as fundamentações da nossa história. Tal fundamentação assistirá nossa circulação pelos "cômodos" na casa da existência, cômodos como a sociedade, a cultura e, também, a educação. Eles são a nossa vivência, nossas interações sociais e culturais; já o "porão" é a base que nos desobstrui o olhar, que nos faz compreender da

\footnotetext{
${ }^{1}$ Universidade Federal do Espírito Santo, Vitória - ES, jlsporto@gmail.com

2 Universidade Federal do Espírito Santo, Vitória - ES, hiranpinel@gmail.com

${ }^{3}$ Universidade Federal do Espírito Santo, Vitória - ES, adriana.r.magro@gmail.com
} 
dinâmica do "porquê" e do "como" vivemos, que informa e nos deixa compreender a arquitetura desses cômodos-de-conviver, também nos faz não negar nossas utopias, nosso ideal futuro, representados nessa parábola como sendo o nosso "sótão" o andar superior, nosso mundo das ideias, o mundo virgem do imprevisível, do planejável e, permitidamente, do desejável. Nos alerta Veiga-Neto a nos comprometermos com abrir a porta do porão. Verificar nossa história, para uma vivência de completude na casa, nossa ocupação (2012):

\begin{abstract}
Mas, mesmo que acolhidos pela casa, corremos sempre o risco de viver bloqueados, viver no alheamento, isto é, alienados no mundo e do mundo. Isso será assim se não soubermos ocupar toda a casa, se nos mantivermos confinados apenas no espaço intermediário, nesse espaço das experiências imediatas em que se desenrola o que chamamos de vida concreta e de realidade. Se nos deixarmos prender nos andares intermediários, sem habitar o sótão e o porão, perderemos boa parte de nossa própria condição humana, pois, enquanto lá no sótão se dão as experiências da imaginação e da sublimação, é lá no porão que estão as raízes e a sustentação racional da própria casa (p.269).
\end{abstract}

Dessa maneira, dentre os tijolos e vigas que dão base à nossa casa-escola, percebemos que alguns se desgastaram ou foram mal posicionados, trazendo algumas rachaduras à casa, as quais precisamos identificar e tentar recobrir. No rol das rachaduras, encontramos um sistema educacional lutando, à duras penas, com um projeto de "desanalfabetização" que, historicamente, foi mal fundamentado e, agora, tenta remediar, quase que numa ação charlatanesca, para ser inserido no mundo capitalista, industrial e pseudoglobalizado. Chegamos ao ponto em que precisamos nos valer de uma educação voltada exclusivamente aos jovens e adultos, para darmos cabo à garantia de direitos, como a educação e o pertencimento social.

Dos projetos que já avançam há mais de meio século, a preocupação com a Educação de Jovens Adultos vem se firmar, nos últimos dez anos, com as propostas nacionais para essa modalidade e sua relação como o mundo do trabalho, ou mundo do proletariado, como é mais apropriado chamarmos. Encontramos assim, um projeto que nasce no "porão" da exclusão escolar, da invisibilização e da construção de um novo tipo de preconceito - contra os "iletrados" - para um projeto que visa às relações da Educação com o trabalho, com o empoderamento e com a cidadania. Porém, talvez ainda longe de um projeto social, às vistas governamentais, que se apresentasse realmente inclusivo. 
Sair da marginalidade e tornar-se viável, legalmente, trouxe algumas questões de investigação sobre a modalidade Educação de Jovens e Adultos, dentre elas, a necessidade de uma definição de juventude que desestabilize os processos de exclusão, no Ensino Fundamental, de jovens "empurrados" para essa modalidade, sendo destituídos do direito a um atendimento por práticas inclusivas desde o ensino dito "regular". É óbvio o esquecimento e invisibilização de alguns jovens "repetentes" e a ansiedade docente de que, esses, alcancem a idade "jovem" que os retire do Ensino Fundamental. Assim, a Educação de Jovens e Adultos, que deveria ter prazo de validade - ao menos quanto à função reparadora - até a concessão dos direitos escolares às crianças, é retroalimentada e mantida nos modos mais atrozes, distanciando-se de sua ideia inicial.

Justificam-se assim, todos os empenhos na busca de uma compreensão de juventude, para a estabilização legal da Educação de Jovens e Adultos e sua composição como projeto inclusivo que, de fato, reconheça que a tal "aprendizagem no tempo certo" seja a "aprendizagem no tempo de cada um". Estudos e ações de resistência são essenciais para que a Educação se comprometa com o ser - o mesmo ser incompleto de Paulo Freire (1980) - independente da etariedade e do tempo que lhe competem.

Este ensaio teve, metodologicamente, uma inspiração na fenomenologia descritiva imbricada à educação, caracterizando-se por um mergulho no fenômeno da Educação de Jovens e Adultos e nos aproximando das proposições de Chela Sandoval (2000) sobre uma metodologia dos oprimidos que

[...] reconhecendo seus lugares e corpos como narrados pelo e através do corpo social e que são, portanto, conscientemente comprometidos com formas inéditas de linguagem, refazem seus próprios tipos de posição social, utilizando todos os meios à sua disposição - se se trata da narrativa como arma, como motim, como discurso [...] (p.84). ${ }^{4}$

Sob essa alegação - muito própria aos estudos sobre os excluídos -, a dos modos descritivo-reflexivos fenomenológicos, bem como a tentativa de nos aproximarmos de uma

\footnotetext{
${ }^{4}[\ldots]$ recognizing their places and bodies as narrativized by and through the social body, and who are thus selfconsciously committed to unprecedented forms of language, to remaking their own kinds of social position utilizing all media at their disposal - whether it is narrative as weapon, riot as speech, [...].
} 
Metodologia do Oprimido (SANDOVAL, 2000), recuperando o fôlego, trouxemos à tona algumas tensões, inquietações e resistências possíveis na contribuição com a leitura do mundo da Educação de Jovens e Adultos, tomados pelos discursos/experiências ouvidos/narrados/vividos da nossa atuação nessa modalidade, tendo sido esse o nosso objetivo principal.

Esse objetivo foi alcançado com um estudo de caso que, apesar de citar dados quantitativos de uma escola, pretendeu-se qualitativo/descritivo, com uma aposta críticoreflexiva, a partir das vivências dos autores junto aos sujeitos da pesquisa em suas atuações/relações diretas na Educação de Jovens e Adultos como professores, coordenadores e orientadores de pesquisa e estágio supervisionado curricular obrigatório, bem como de nosso envolvimento direto com a Educação Social.

\section{Entremeios etários}

As legendas, na tela da TV que apresentava um programa policial sensacionalista, mostravam "menor, mata adolescente em São Paulo". As câmeras vaguearam e se desfocaram ao mostrar o rapaz. Repórter investigativo, nervoso e histericamente perguntando "você já tinha roubado o menino, por que você o matou?" Com uma voz tranquila, muito serena, ele respondeu: "porque faltam três dias para eu fazer dezoito", suspirou, coçou a cabeça e continuou "três dias para eu ficar adulto e... e... e eu queria experimentar matar alguém".

Quando se começa uma argumentação com uma descrição como do parágrafo anterior, nossa associação é quase direta às discussões sobre a diminuição da maioridade penal. Mas a mensagem oculta, ou currículo social oculto, quase subliminar, remete, de fato, às discussões sobre os conceitos de infância, adolescência e juventude que se entrelaçam no campo das leis e da Educação no Brasil. Tão complexos e desacordados são esses conceitos que a legenda do programa de TV marca uma diferença expressa na frase "menor mata um adolescente", quando ambos os termos deveriam remeter ao mesmo significado para ambos os indivíduos. Porém, e para além dos vazios conceituais sobre juventude, o pouco que se tem ainda é categorizado, no espaço de injustiças sociais, talvez não para a construção específica da categoria, mas para marcar um campo de exclusão que justifica o não comprometimento com o "menor" em detrimento do comprometimento com o "adolescente". 
Nesse entremeio tão complexo, da infância com a adolescência e adultez, a denominação 'menor', com suas subjetivações e classificações de construto social (ROSA, 2004), se localiza no infrator que ainda não completou dezoito anos e a classificação 'adolescente', mais do que associado a uma faixa etária, associa-se ao escolarizado, ao vitimado, também com menos de dezoito. Para Sposito e Carrano (2003, p.20), "Ocorre uma convivência tensa entre a luta por uma nova concepção de direitos a essa fase da vida e a reiterada forma de separar a criança e o adolescente das elites do 'outro', não mais criança ou adolescente, mas delinquente, perigoso, virtual ameaça à ordem social".

Gonçalves (2003), analisando a construção do conceito de adolescência, bem como do estereótipo do adolescente, nos meios televisivos, traz à tona os fatores "gourmetizantes" de um tipo de adolescência que realça o abismo entre equivocada construção de adolescênciamenor em relação à adolescência-adolescência. A autora considera que a televisão mantém a naturalização desse estereótipo e uma percepção 'a-histórica' dos conceitos de adolescente e adolescência.

Ainda sobre as classificações, Cesconetto et al. (2006), ao analisarem a representação jornalística sobre a adolescência, num estudo realizado sobre juventude capixaba e a mídia em 2003, constataram que o termo "menor" foi frequentemente retratado nas colunas sobre violência. Sobre essa pesquisa e seus resultados, uma importante avaliação foi feita por Rosa, Ribeiro Júnior e Rangel (2007).

Embora o Estatuto da Criança e do Adolescente tenha abolido o termo menor, pelo menos do texto da Lei, 13 anos antes da publicação das matérias ele foi utilizado em $7 \%$ das reportagens, sendo observado, no entanto, que quase sempre o termo era usado para referir-se ao jovem autor de ato infracional, assim como a expressão desempregado. Já o termo trabalhador, que também aparece com frequência nas páginas policiais, refere-se sempre à vítima (p.52).

O adolescente-menor entrevistado, citado no primeiro parágrafo desse capítulo, aproveita a diferença de setenta e duas horas entre a infância, ou adolescência ou juventude e a fase adulta, para experimentar sua sociopatia. O repórter questiona conceitos de juventude e maioridade penal e acaba sendo um interlocutor-intérprete na mensagem sobre a proposta de uma nova definição do que é infância e juventude e do que é ser adulto. Ser adulto é poder 
matar. Assim, o currículo oculto (ANYON, 1980) é ensinado implicitamente, porém com uma aprendizagem explícita e, nesse caso, acaba por propor uma grotesca e perigosa diferenciação entre a juventude e a adultez.

O entremeio etário é tão tênue e fluído que afeta várias áreas sociais. Não conseguimos, em pleno século XXI, uma definição específica sobre as condições e classificações etárias. Ora, uma vez dançando entre esses arranjos, é lúcido perguntar: sem saber o que é infância, adolescência, juventude e adultez, é possível assumirmos políticas específicas de cuidado e educação específicos para cada uma dessas categorias?

\section{Das fronteiras para os não lugares}

Ariès (2017) prega o quanto foi e é incansável uma busca social pela significação do que é ser criança, do que é infância e onde começa a juventude e a vida adulta. Na atualidade, crianças já foram consideradas meros seres biológicos e isso nos remete ao termo pejorativo 'menor', como resquício da Infância Negada. De fato, somente a modernidade trouxe uma ideia de infância, porém pautada em normas e prescrições que, segundo Sarmento (2003), constrangem as vidas das crianças com suas delimitações espaciais, alimentícias, autorizações para participação na vida coletiva etc. $\mathrm{O}$ autor crê ainda que a ideia moderna de infância está intimamente ligada às atividades escolares que traçam um comportamento padrão aceitável para sua consideração de "ser criança", logo, o de não ser menor.

No Brasil, a ideia sobre o que é ser uma criança e adolescente, tem raízes produtoras de políticas públicas na formulação de um Estatuto da Criança e do Adolescente (ECA) - Lei n 8.069 de 13 de julho de 1990, no artigo $2^{\circ}$ - que acaba por definir e decidir que, "Considera-se criança, para os efeitos desta Lei, a pessoa até doze anos de idade incompletos e, adolescente, aquela entre doze e dezoito anos de idade" (BRASIL, 1990).

Também a ideia de juventude, segundo Groppo (2000), fundamenta-se, basicamente, em dois critérios: o etário e o sociocultural. O etário, considerado principalmente sob a ótica da legalidade, nos apresenta - com precedentes de dúvidas - uma juventude que se mistura à adolescência nos Estatutos da Criança e do Adolescente e Estatuto da Juventude. O critério etário então, para a juventude, segundo a lei 12.852 de 5 de agosto de 2013, define (BRASIL, 2013) 
$\S 1$ o Para os efeitos desta Lei, são consideradas jovens as pessoas com idade entre 15 (quinze) e 29 (vinte e nove) anos de idade.

$\S 2$ 을 Aos adolescentes com idade entre 15 (quinze) e 18 (dezoito) anos aplica-se a Lei no 8.069, de 13 de julho de 1990 - Estatuto da Criança e do Adolescente, e, excepcionalmente, este Estatuto, quando não conflitar com as normas de proteção integral do adolescente.

Para a Organização Pan-Americana da Saúde e Organização Mundial da Saúde (OPS/OMS), a categoria juventude tem um cunho sociológico e é definida pelo período etário compreendido entre 15 e 24 anos. Em suma, temos a seguinte classificação:

Quadro 1 - Classificação de juventude

\begin{tabular}{|c|c|c|c|c|}
\hline Instituições/Lei & INFÂNCIA & ADOLESCÊNCIA & JUVENTUDE & ADULTEZ \\
\hline $\begin{array}{l}\text { Estatuto da } \\
\text { Criança e do } \\
\text { Adolescente }\end{array}$ & $0-12$ anos & $12-18$ anos & - & $\begin{array}{c}\text { Acima de } 18 \text { anos } \\
\text { (por dedução) }\end{array}$ \\
\hline $\begin{array}{l}\text { Estatuto da } \\
\text { Juventude }\end{array}$ & $\begin{array}{c}0-15 \text { anos } \\
\text { (por dedução) }\end{array}$ & $15-18$ anos (?) & $15-29$ anos & $\begin{array}{l}\text { Acima de } 29 \text { anos } \\
\text { (por dedução) }\end{array}$ \\
\hline $\begin{array}{l}\text { Organização } \\
\text { Mundial de } \\
\text { Saúde }\end{array}$ & $\begin{array}{c}0-15 \text { anos } \\
\text { (por dedução) }\end{array}$ & - & $15-24$ anos & $\begin{array}{l}\text { Acima de } 24 \text { anos } \\
\text { (por dedução) }\end{array}$ \\
\hline
\end{tabular}

Fonte: Autoria própria

Ainda, para efeitos legais, temos o Estatuto da Criança e do Adolescente prevendo que, por exemplo, é considerado Trabalho Infantil abaixo dos 16 anos, porém a permissão da Aprendizagem (anteriormente chamada Menor Aprendiz) acima dos 14 anos de idade.

Numa representação Gráfica verificamos um nicho etário, um entremeio que vai dos quinze aos dezoito anos. 
Figura 1 - Nicho etário entre as idades

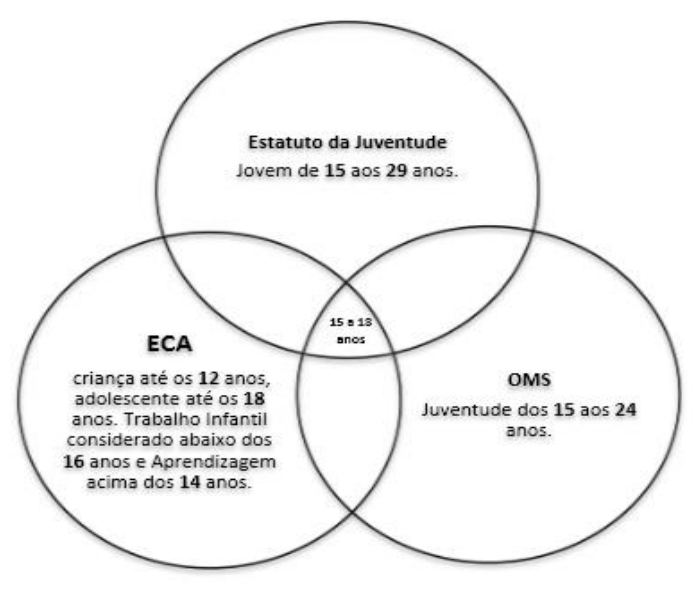

Fonte: Autoria própria

Assim, as organizações e instrumentos legais, acabam por criar um vácuo etário, uma zona fantasma, uma região onde, de fato, sem identidade, esse grupo é invisibilizado por todas as organizações. Sem uma delimitação específica de "responsabilidade sobre". Um exemplo disso encontra-se no Atlas da Violência (CERQUEIRA et al, 2018) que esclarece:

A vitimização por homicídio de jovens (15 a 29 anos) no país é fenômeno denunciado ao longo das últimas décadas, mas que permanece sem a devida resposta em termos de políticas públicas que efetivamente venham a enfrentar o problema. Os dados de 2016 indicam o agravamento do quadro em boa parte do país: os jovens, sobretudo os homens, seguem prematuramente perdendo as suas vidas. (p.32).

Também retrata, o Conselho Nacional de Justiça, um quadro onde o maior índice de jovens em medida socioeducativa no país está na faixa entre 15 e 18 anos, cerca de 130 mil. Para Groppo (2000), o segundo critério para definir o que é ser jovem, no Brasil, é o sociocultural. Atualmente a juventude tem sido definida, sob essa perspectiva, observando-se a classe social, os grupos étnicos, a nacionalidade, o gênero, concomitantemente às questões de tempo. 0 entremeio etário acaba sendo respaldado pelo entremeio da exclusão e estereotipação da juventude, ainda confundida com infância, adolescência e adultez, traduzida numa zona fantasma etária, num não lugar. 


\section{Dos não lugares para o lugar-escola}

Segundo a Lei no 13.632, de 6 de março de 2018, o Art. 1ํ A Lei no 9.394, de 20 de dezembro de 1996 (Lei de Diretrizes e Bases da Educação Nacional), passa a vigorar com a seguinte redação:

XIII - garantia do direito à educação e à aprendizagem ao longo da vida."

"Art. 37. A educação de jovens e adultos será destinada àqueles que não tiveram acesso ou continuidade de estudos nos ensinos fundamental e médio na idade própria e constituirá instrumento para a educação e a aprendizagem ao longo da vida (BRASIL, 1996).

$\mathrm{Na}$ interseção do gráfico 1, o "entremeio etário" apresentado - entre 15 e 18 anos surge, a partir das tentativas desarticuladas de manutenção de políticas específicas, como um fenômeno, como uma categoria que, culturalmente, a Escola começa a considerar como jovens. Mais uma apropriação desconexa que garante desentendimentos, invisibilizações e desvios nas políticas de direitos para esse grupo. Sob essa alcunha, justifica-se a entrada em massa de crianças-jovens-adultos na modalidade da Educação de Jovens e Adultos, EJA, no Ensino Fundamental e como ensino noturno.

Como materialização disso, por exemplo, na modalidade EJA de uma Escola Municipal de Ensino Fundamental, na cidade de Vitória no Estado do Espírito Santo, verificou-se que, das matrículas e rematrículas efetuadas, cerca de 50\% eram crianças-jovens-adultos entre 15 e 18 anos e que, dentre essas matrículas e rematrículas, $61 \%$ dos matriculados se autodeclararam ${ }^{5}$ do sexo masculino. Ainda, segundo o Censo Escolar (INEP, 2017), a Educação de Jovens e Adultos (EJA) no Brasil, registrou aumento de $4,1 \%$ no número de matriculados o que equivale a 2,92 milhões de estudantes. Porém esse número está relacionado a matrículas também no Ensino Médio, onde é permitida apenas a entrada a partir dos 18 anos.

As definições etárias auxiliam num reconhecimento legal da infância, adolescência e juventude e, a partir delas, um reconhecimento cultural e de direitos. Essas mesmas definições afastam o conflito e acendem a linha tênue que as separa - ou une - para uma aquisição distinta

\footnotetext{
${ }^{5}$ Faz-se importante mencionar que, nessa Unidade de Ensino, especificamente, tanto os dados de etnia quanto os de sexo e de gênero são feitos por autodeclaração.
}

Periódico Horizontes - USF - Itatiba, SP - Brasil - e020020 
de direitos. Se não consideramos isso, então não poderemos contribuir na visibilização e inclusão, no atendimento escolar, na formação do profissional da EJA e nem questionar sobre os atuais projetos de "alfabetização na idade certa", como consta, por exemplo, o do PNAIC (Pacto Nacional pela Alfabetização na Idade Certa), que deveriam ser revisitados em suas propostas para que nossos jovens - se é que há um consenso geral sobre essa categoria - percebam que "não perderam tempo", que não precisam "correr atrás do prejuízo", mas de que a Educação, em qualquer tempo, Ihes seja uma questão de direitos e que, direitos, não podem ser negados.

Mas por que ainda, do não lugar, as crianças-adolescentes-jovens têm, massivamente, ocupado a modalidade Educação de Jovens e Adultos se, segundo o Estatuto da Criança e do Adolescente (BRASIL, 1990) - Lei no 8.069 de 13 de Julho de 1990, no artigo 53, "a criança e o adolescente têm direito à educação, visando ao pleno desenvolvimento de sua pessoa, preparo para o exercício da cidadania e qualificação para o trabalho, assegurando-lhe:" diz o inciso I, "igualdade de condições para o acesso e permanência na escola"? Por que o Brasil ainda produz o "sujeito" do analfabetismo? Por que a Educação de Jovens e Adultos, ano a ano, é retroalimentada por uma horda de "indefinidos" etariamente?

Existe, desse entremeio etário, um público elevado de acessos à modalidade da Educação de Jovens e Adultos, principalmente equivalente ao Ensino Fundamental, dito regular. Por que esse fenômeno se dá quase 30 anos depois da elaboração de uma Lei que garante o acesso à educação? Por que ainda a "Geração Escola" representa $50 \%$ por cento da modalidade reparadora de EJA e por que $51 \%$ da população acima de 25 anos no Brasil tem apenas o Ensino Fundamental completo?

\section{Educação de Jovens e Adultos: por que e para quem?}

No "porão" da Educação Brasileira, temos um comodismo social quanto às questões de aquisição de leitura e escrita que inscreveram o Brasil, na atualidade, como um dos países, em desenvolvimento, com altos índices de analfabetismo. Desconsiderando os outros analfabetismos, o mais urgente, o de leitura e escrita coloca o Brasil com cerca de 12 milhões de analfabetos, segundo a Pesquisa Nacional por Amostra de Domicílios Contínua, se referindo ao ano de 2016 . Isso representa 7,5\% da população acima de 15 anos de idade. 
Segundo o Parecer CNE/CEB n 11/2000

[...] a Educação de Jovens e Adultos (EJA) representa uma dívida social não reparada para com os que não tiveram acesso a e nem domínio da escrita e leitura como bens sociais, na escola ou fora dela, e tenham sido a força de trabalho empregada na constituição de riquezas e na elevação de obras públicas. Ser privado deste acesso é, de fato, a perda de um instrumento imprescindível para uma presença significativa na convivência social contemporânea (BRASIL, 2010, p.5).

Dessa maneira, o leitmotiv da Educação de Jovens e Adultos tem o foco na função reparadora e, veementemente, essa, não pode ser confundida com suprimento, com doação. Todos nós caminhamos numa linha de direitos, ou ao menos deveríamos. Exclusão - no caso escolar - é o afastamento dos sujeitos dessa linha de direitos, uma negação de pertencimento ao mundo dito letrado. Assim, precisamos ter cautela, quando da garantia de retorno desses sujeitos a essa linha, pois não é um presente ou recuperação de tempo, talvez devamos pôr em cheque até o termo inclusão. Não sendo um ato de bondade, a Educação de Jovens e Adultos é um instrumento de recuperação, desses sujeitos, do direito à escolarização e alfabetização, bem como o da garantia de pertencimento social.

Pensando na função reparadora da Educação de Jovens e Adultos, nos levantamentos censitários sobre analfabetismo, nas indefinições etárias para produção de políticas específicas, em quase trinta anos do Estatuto da Criança e do Adolescente como garantia de acesso à educação, nos elevados índices de evasão escolar, bem como na juvenização da EJA, talvez possamos provocar sobre por que, ainda, a Educação de Jovens e Adultos, não cumpriu sua função reparadora.

\section{Os "novos" sujeitos na Educação de Jovens e Adultos}

Mesmo da complexidade do ser humano e das suas resistências às produções sociais, é necessário, para fins de educação/erradicação dos "analfabetismos" e produção de políticas específicas de inclusão e reparo, uma definição legal sobre, pelo menos, três categorias etárias: infância, juventude e adultez.

Uma possibilidade, quanto à Educação de Jovens e Adultos, é de que haja uma definição 
de "juventude", da mesma forma que para outras categorias baseadas na construção etária, sendo essa definição fundamental para o entendimento das sociedades na modernidade, suas transformações e funcionamento. Se juventude e adultez estão no campo da fluidez e, determinar fronteiras não devesse ser o foco, talvez devamos considerar a afirmação de Bourdieu (2003) que:

A idade é um dado biológico socialmente manipulado e manipulável; e que o fato de se falar dos jovens como de uma unidade social, de um grupo constituído, dotado de interesses comuns, e de se referir esses interesses a uma idade definida biologicamente, constitui já uma evidente manipulação (p.153).

Porém, a modalidade de Educação de Jovens e Adultos, um fenômeno quase que exclusivo dos países em desenvolvimento, precisa de algumas alternativas para a garantia de alguns direitos.

Para efeito, em países como o Brasil, longe da discussão da manipulação "social" dos conceitos de juventude - uma vez que já existe uma lei com delimitação do que é infância e seus direitos -, talvez fosse apropriado considerar a delimitação etária de juventude.

Precisamos recordar que estamos "metidos" nesse fenômeno e que, talvez, seja mais apropriado olharmos para ele juntamente com seus sujeitos.

Também é previsível que, sem essa definição, haja um colapso nos projetos de erradicação do analfabetismo e de inclusão escolar, se consideramos que, cada vez mais novos, as criançasadolescentes-jovens são direcionados "ao campo de concentração dos excluídos" por uma falta de estratégias e ações preventivas no Ensino Fundamental. Se essas etariedades fossem bem definidas, sim, as políticas voltadas para as mesmas, principalmente quanto à educação - seja lá onde essa ocorra - seriam conduzidas e aplicadas de maneira mais efetiva ao passo que, ignorar a necessidade dessas definições, parece promover um descompromisso e uma "passada de bastão" para a EJA das ainda "crianças-adolescentes" vindas de "produções de fracassos" do Ensino Fundamental.

\section{Os minorados e Educação de Jovens e Adultos}

Por anos desgastamos o tratado das "minorias" e naturalizamos, tal qual os preconceitos que nos afastam da linha de direitos, o sentido do termo. Apesar de amenizarmos os discursos 
dizendo que as "minorias" não são quantitativas, a exemplo no Brasil das mulheres e negros, mas subjetivadas no quesito de "relação à concessão de direitos", continuamos não percebendo que o termo coloca as mesmas minorias, numa posição ativa e de coparticipação dos processos de sua própria exclusão. Não se escolhe ser minoria. É uma posição política e de negação de direitos imposta. Se nos voltarmos a Arendt (2006) percebemos que

\begin{abstract}
Algo mais fundamental do que a liberdade e a justiça, que são os direitos do cidadão, está em jogo quando deixa de ser natural que um homem pertença a uma comunidade em que nasceu, e quando o não pertencer a ela não é um ato da sua livre escolha [...] São privados não de seu direito à liberdade, mas do direito à ação; não do direito de pensarem o que quiserem, mas do direito de opinarem. Privilégios (em alguns casos), injustiças (na maioria das vezes) bênçãos ou ruínas lhes serão dados ao sabor do acaso e sem qualquer relação com o que fazem, fizeram ou venham a fazer (p.330). [grifo nosso]
\end{abstract}

Assim, não são "minorias", mesmo acompanhadas do termo "políticas" ou "de direitos", são minorizados. Aqueles que são postos nesse lugar, ou seja, aqueles que são posicionados e condicionados contra sua própria vontade ao lugar da exclusão. Nesses termos o condicionamento, para além do afastamento de seus lugares de direito, se complementa na alienação e acomodação dos minorizados nessa posição a qual insistimos chamar "minorias". Ao contrário disso, quando da libertação pela educação formal ou não formal, vemos em Patto (2010) e Freire (1975) o surgimento da resistência.

No caso dos nossos indefinidos etariamente, os quais mapeamos na interseção das políticas perdidas de não definição "infância-juventude-adultez", alguns instrumentos são utilizados para sua minorização, infelizmente, tendo o amparo no sistema de educação vigente, principalmente no Ensino Fundamental.

Assim, para classificarmos um ensino como "regular", fazemos uma manutenção simbólica de um ensino pejorativizado como "irregular", retroalimentando-o pela exclusão, essa preenchida com a "minorização" que imputamos aos "irregulares desse sistema". Eis aí os "novos" sujeitos da Educação de Jovens e Adultos que, para além da produção clássica de décadas anteriores - atrelada à pobreza, à condição de classe social, de etnia, às questões patriarcalistas e de negação de direito -, porém hoje, sob a égide de uma pretensa era da infância dos sujeitos de direitos, garantida pelo Estatuto da Criança e do Adolescente, minorizam sujeitos 
pelos instrumentos que "regularizam" esse ensino, dentre os quais destacamos o currículo, a avaliação e a reprovação.

\section{O currículo}

No livro "Documentos de Identidade: uma introdução às teorias de currículo" (SILVA, 2015) são mapeadas as principais teorias que determinam o currículo como representação e reprodução social dentro do sistema educacional. Assim, parece que uma sociedade que carece de justiça social, por exemplo, tem um currículo que reproduz essa mesma falta de justiça dentro dos limites da escola. Também informa das Teorias Críticas e Pós-Críticas que relacionam o currículo como um dos principais instrumentos de perpetuação da minorização dos sujeitos categorizando-o como branco, hetero-macho-normativo e burguês. No entanto, para Anyon (1980), como profissionais da educação, repetimos o currículo pelo qual passamos em nossa formação e, assim, faz-se uma manutenção da exclusão que o mesmo produz, uma ideia que parece reverberar em autores como Apple (2003), Giroux (1997) e MacLaren (1997). Para Porto (2018),

Como é manifesto do currículo escolar, põe-se a mesa com todas as iguariassaberes inimagináveis e saborosamente atrativos, os estudantes-convidados sentam-se, veem toda a cornucópia profusão de guloseimas, porém, ao final, Ihes é servido o que, exatamente, o currículo-opressor determinou. Temos clareza que, ocultamente, esse cardápio-currículo tem seus propósitos. Ao fim, os intolerantes, alérgicos e resistentes se negam a comer o que lhes faz muito mal, bem como o que não lhes agrada, retiram-se-são-retirados da mesa e assim começa a "pré-história" da exclusão provocada pela própria escola (p.2).

O currículo prescrito, por fim, não alcança a diversidade dentro de uma sala de aula no ensino, dito regular, nulo (ANYON, 1980) ele invisibiliza o currículo vivido dos estudantes. Nele apropriado como instrumento de exclusão - não são comportadas as gravidezes nas adolescências, os gêneros autodeclarados, as diversidades sexuais, as diversidades étnicoraciais, as pobrezas diversas, as fomes possíveis, as deficiências intelectuais, as resistências insurgentes, entre tantas outras. Ao contrário, oculto, conforme o mesmo auto, ele se traduz na aprendizagem explícita de ensinamentos simbólico-violentos implícitos. Não suportando essa prescrição estrita, estudantes se "rebelam", não aceitam comer dessa mesa, querem "comer" o 
que podem ver, mas que não lhes é permitido, não aceitam o que o sistema escolhe por eles.

Assim, sendo acometido por avaliações padronizadas injustas, por uma perpetuação de ameaças, pelo cerceamento ao direito à aprendizagem, começam o processo atroz de "desregularização do fluxo", de desmantelamento conhecida como "distorção idade-série". Distorção não suportada pela prescrição higienista, pelo aprisionamento estatístico, pelas siglas (des)classificadoras com vistas numa divisão efetiva de classes. Dessa maneira, evadem do ensino, dito regular, quando não, são encaminhados ao limbo estigmatizado pela Exclusão Escolar: a modalidade EJA.

\section{A avaliação e reprovação}

A avaliação, como instrumento, teve um início conturbado com o surgimento da Escola. Por esse início, até hoje, confundimos "exames" com "avaliação". Passou também por uma reformulação, atrelada ao currículo e voltada à aprendizagem, como tentativa, por Ralph Tyler (SILVA, 2015), de resolução dos índices de reprovação desde a década de 1930. Seu caráter classificatório e seletivo deveria ter sido execrado da educação, desde então, para constituir-se de um instrumento de diagnóstico e, quem sabe, inclusivo.

Por que avaliamos na escola? Essa é uma pergunta que deveria ser recorrente nas formações iniciais de professores. O que de fato é uma avaliação escolar? Sua característica principal é a de ser quantitativa, qualitativa ou ambas? Por que a avaliação escolar é a finalização de um processo e não o início de um novo processo numa perspectiva diagnóstica? Ela serve como instrumento de aprendizagem ou de ameaça?

Fato é que, na avaliação escolar, ainda prefigura o medo pregado por Comenius como a maneira de "prender a atenção dos alunos". Ela se tornou uma ameaça, uma punição, uma elaboração refinada de poderio sobre o outro, do vigiar e punir foucaulteano. Temos hoje na avaliação escolar um instrumento eficaz no posicionamento dos "minorizados" como excluídos da Escola e, nos últimos anos, ainda traduzida como (PORTO, 2013) ferramenta neoliberal e de sujeição de classes pelos testes padronizados.

Numa visão crítica, a avaliação escolar é explicada cruamente por Arroyo e Fernandes (1999, p.29). 
Eu lembro que um colega Chileno, um dia me perguntou: "O Brasil é o país mais avançado da América Latina, a economia mais avançada! E vocês são o segundo em analfabetismo na América Latina, 30 milhões, como é possível? Vocês têm fama de ter tendências educativas avançadas. Paulo Freire está aí! O movimento de renovação pedagógica está aí. Florestan Fernandes está aí. Como é possível tantos analfabetos na cidade e no campo?" Respondi: Porque nós temos o sistema educativo mais seletivo da América Latina, que cria analfabetos, ele, o próprio sistema. Quando um adolescente repete três, quatro, cinco vezes, vai ficando convencido que é burro, porque a escola lhe diz que é burro e o pai se convence e diz: "A cabeça do meu filho não é feita para as letras. Vai trabalhar com a enxada". Não é isso que acontece?

A provável ideia a qual se tem negado como sistema educacional é que, na escola, se avalia para reprovar. A educação, logo, se faz competitiva e não colaborativa, havendo assim "vencedores" e "perdedores". Dentro desse quadro patológico - do sistema -torna-se claro, para os estudantes, o propósito das reprovações contínuas e regulares: os "aprovados-vencedores" serão os socialmente inscritos e os "reprovados-perdedores", os proscritos. E como não se pode macular a superiorização da "aprendizagem na idade certa" com a equivocada distorção idadesérie, é utilizado um funil-educacional chamado EJA que culmina num poço de evasão. Esse método injusto de desclassificação posiciona a EJA como um local de abandono da escola quando, de fato, essa evasão e abandono deveriam achar seu cerne de responsabilização no ensino, dito regular, corrompido, por um currículo equivocado e um sistema avaliativo injusto.

Temos utilizado o não lugar construído pela ausência de adoção por políticas específicas, o entremeio etário dos 15 aos 18 anos, como base para uma retroalimentação da Educação de Jovens e Adultos. Reprovamos os alunos até que completem 15 anos e nos livramos do “problema” na nossa "educação seletiva". Produzimos os vírus para garantir a venda do antivírus.

\section{Considerações finais: o elefante na sala}

Politicamente no Brasil, como nação, não foram garantidos, a contento, o direito e o acesso à Educação, como previsto no Estatuto da Criança e do Adolescente - ECA (1990), para todos os classificados como beneficiários dessa Lei. Em três décadas, o sistema de Educação brasileiro deveria ter, na Educação de Jovens e Adultos, um corpo discente formado apenas por estudantes acima de quarenta anos, ou seja, adultos, de acordo com as classificações vigentes, 
considerando sua proposta de reparação da exclusão escolar promovida nas décadas anteriores a de 1980, negando-se veementemente à correção de fluxo, discutível, da distorção idade-série como vista no ensino, dito regular. Ao contrário disso, hoje, contamos com um número expressivo de crianças-adolescentes-jovens na EJA, chegando à quase metade dos atendidos nessa modalidade.

O elefante na sala, sobre o qual toda a "família-educação" se nega a falar, é o desajustado dentre todos os parentes, o ensino, dito regular, que tem sido utilizado para a acomodação na falta de políticas públicas específicas para as faixas etárias que carecem de uma atenção pontual, que tem exaltado a prática das reprovações, dos testes padronizados, que tem se submetido à aplicação de um currículo que exclui e minoriza os diferentes, os não uniformes - mesmo de uniformes - que não condizem com "um mesmo remédio aplicado para variadas doenças". Nãose-consegue-é-permitido falar da infração institucionalizada, do ensino, dito regular 'meliante' que, contra a Lei, emancipa por imposição crianças-adolescentes-jovens ao patamar de adultos. Um ensino que, violentamente, impõe aos seus o fardo de um fracasso que não é e nunca será do estudante, mas sim, um fracasso escolar, quando escolar se refere certeiramente ao fracasso "da escola" em relação aos mesmos. A despeito de todas as discussões francesas, de séculos atrás, sobre a "aprendizagem ao longo da vida" e a gadottiana (GADOTTI, 1981) discussão da "educação ao longo da vida", o que talvez nos falta é a compreensão de todas as vidas minorizadas ao longo da, teorizada, vida.

\section{Referências}

ANYON, J. Social class and the hidden curriculum of work. Journal of Education, v.162, n. 1, fall 1980. Disponível em: https://journals.sagepub.com/doi/10.1177/002205748016200106. Acesso em 23 de Jan de 2019.

ARENDT, H. Origens do totalitarismo. São Paulo: Companhia das Letras, 2006.

ARIÈS, P. A história social da infância e da família. Rio de Janeiro: LTC, 2017.

ARROYO, M. G.; FERNANDES, B. M. A educação básica e o movimento social do campo. Brasília: DF, 1999.

APPLE, M. Educando à direita: mercados, padrões, Deus e a desigualdade. Trad. Dinah Abreu de 
Azevedo. São Paulo: Cortez: Instituto Paulo Freire, 2003.

BACHELARD, G. A poética do espaço. São Paulo: Martins Fontes, 2003.

BOURDIEU, P. Questões de sociologia. Trad. M. S. Pereira. Lisboa :Fim de Século / Sociedade Unipessoal, 2003.

BRASIL. Estatuto da Criança e do Adolescente: ECA. Brasília, DF: 1990.

BRASIL. Lei de Diretrizes e Bases da Educação Nacional. Brasília, DF:1996.

BRASIL. Parecer CEB/CNE $n^{\circ}$ 11/2000: Diretrizes Curriculares Nacionais para a Educação de Jovens e Adultos. Brasília, DF: 2010.

BRASIL. Estatuto da Juventude. Brasília, DF: 2013

CERQUEIRA, D. et al. Atlas da violência. Brasília, DF: Ipea, 2018.

CESCONETTO, C. Z. et al. Juventude e mídia: uma análise dos jornais A Gazeta e A Tribuna. Vitória, ES: EDUFES, 2006.

FREIRE, P. Pedagogia do oprimido. Rio de Janeiro: Paz e Terra, 1975.

. Educação como prática de liberdade. Rio de Janeiro: Paz e Terra, 1980.

GADOTTI, M. A educação contra a educação: o esquecimento da educação através da educação Permanente. Rio de Janeiro: Paz e Terra, 1981.

GIROUX, H. Os professores como intelectuais: rumo a uma nova pedagogia crítica da aprendizagem. Porto Alegre: Artes Médicas, 1997.

GONÇALVES, M. G. M. Concepções de adolescência veiculadas pela mídia televisiva: um estudo das produções dirigidas aos jovens. In: OZELLA, S. (Org.). Adolescências construídas: a visão da psicologia sócio-histórica. São Paulo: Cortez, 2003. p.41-62.

GROPPO, L. A. Ensaios sobre sociologia e história das juventudes modernas. Rio de Janeiro: Difel, 2000.

INSTITUTO NACIONAL DE ESTUDOS E PESQUISAS EDUCACIONAIS ANÍSIO TEIXEIRA (INEP). Censo Escolar, 2016. Brasília: MEC, 2017.

MACLAREN, P. A vida nas escolas: uma introdução à pedagogia crítica nos fundamentos da educação. Porto Alegre: Artes Médicas, 1997.

PATTO, M. H. S. Produção do fracasso escolar. São Paulo: Casa do Psicólogo, 2010. 
PORTO, J. L. S. Esperando o superman: da diáspora do conceito e sua produção de diferenças e de resistências em escolas no norte e sul globais. 2013. 147p. Tese (Doutorado em Educação) Programa de Pós-Gradução em Educação, Centro de Educação da Universidade Federal do Espírito Santo PPGE-CE-UFES, Vitória-ES, 2013.

PORTO, J. L. S. Naquela rua tem uma cidade: a educação social de jovens e adultos em situação de rua. Vitória, ES: EDUFES, 2018.

ROSA, E. M. Radiografia de um processo social: um estudo sobre o discurso jurídico a respeito da violência contra crianças. São Paulo: Casa do Psicólogo, 2004.

ROSA, E. M.; RIBEIRO JÚNIOR, H.; RANGEL, P.C. $O$ adolescente: a lei e o ato infracional. Vitória, ES: EDUFES, 2007.

SANDOVAL, C. Methodology of the oppressed. Minneapolis: University of Minnesota Press, 2000.

SARMENTO, M. J. As culturas da infância nas encruzilhadas da $2^{a}$ modernidade. Braga: Instituto de Estudos da Criança, Universidade do Minho, 2003.

SILVA, Tomaz Tadeu da. Documentos de Identidade: uma introdução às teorias do currículo. Belo Horizonte: Autêntica Editora, 2015.

SPOSITO, M. P.; CARRANO, P.C. R. Juventude e políticas públicas no Brasil. Revista Brasileira de Educação, Rio de Janeiro, n.24, p.16-39. 2003.

VEIGA-NETO, A. J. É preciso ir aos porões. Revista Brasileira de Educação. Campinas, SP: v.17, n.50, p.267-282, mai./ago. 2012.

Recebido em abril 2019.

Aprovado em janeiro 2020. 